\title{
Pulmonary Embolism Following Outpatient Vasectomy
}

\author{
Frank E. Mott Bilal Farooqi Harry Moore \\ Georgia Regents University Cancer Center, Augusta, Ga., USA
}

\author{
Key Words \\ Vasectomy • Pulmonary embolism • Thrombophlebitis • \\ Thromboembolism risk factors
}

\begin{abstract}
Venous thromboembolic events have several known major risk factors such as prolonged immobilization or major surgery. Pulmonary embolism has rarely been reported after an outpatient vasectomy was completed. We present the rare case of a healthy 32-year-old Caucasian male with no known risk factors who presented with pleuritic chest pain 26 days after his outpatient vasectomy was performed. Subsequently, he was found to have a pulmonary embolism as per radiological imaging. We explore the association between outpatient vasectomies and venous thromboembolic events. A review of the literature is also included.
\end{abstract}

Copyright $\odot 2015$ S. Karger AG, Basel

\section{Introduction}

There are several known major risk-factors for venous thromboembolism. Minor procedures, such as an outpatient vasectomy have rarely been reported and are not considered major risk-factors. We present a unique case presentation of a healthy 32-year-old male who pre-

\section{KARGER}

Fax +4161306 1234

E-Mail karger@karger.ch

www.karger.com
(C) 2015 S. Karger AG, Basel

1015-9770/14/0091-0051\$38.00/0

Accessible online at:

www.karger.com/cur sented with a pulmonary embolism shortly after having an outpatient vasectomy performed. It is important to be aware of such presentations so that physicians can easily recognize them when they present in their own clinical setting.

\section{Case Report}

A 32-year-old Caucasian male with a past medical history of exertional compartment syndrome presented to the Emergency Department for left-sided unremitting pleuritic chest pain. The pain was exacerbated with deep inspiration and was not relieved by a non-steroidal anti-inflammatory drug or a muscle relaxant. He complained of associated shortness of breath. Of note was that the patient underwent a bilateral vasectomy and a left hydrocelectomy 26 days prior to presentation.

No personal or family history of venous thromboembolic events was noted. The patient was active and played basketball recreationally. He did not smoke tobacco or partake in illicit drug use. He drank alcohol occasionally. He was a physician himself. He was married with children.

On physical exam, patient was tachycardia with a heart rate of $106 /$ minute. Respiratory rate was $16 /$ minute. Blood pressure was $117 / 64 \mathrm{mmHg}$. Patient was saturating on room air at $94 \%$. Physical exam revealed no abnormality except the patient's tachycardia.

On laboratory studies, patient's complete blood count showed the patient to be slightly anemic with hemoglobin of $13.8 \mathrm{~g} / \mathrm{dl}$ and hematocrit of $39.9 \%$. White blood cell count was $10.2 \times 10^{9} / 1$ and platelets were $172 \times 10^{9} / 1$. Partial thromboplastin time was within normal limits at 31.0 and the international normalized ratio was also within range at 1.0. D-dimer was elevated at $510 \mathrm{ng} / \mathrm{dl}$.

On imaging, bilateral ultrasound of the lower extremities failed to show any evidence of deep vein thrombosis. However, a CT-Angiography of the chest showed segmental and subseg- 
mental left lower lobe pulmonary emboli with small pulmonary infarction. Heparin drip was started on the patient. Warfarin was also initiated in the patient and bridged with heparin until the patient's international normalized ratio was in the therapeutic range. Patient's symptoms improved and he was eventually stable for discharge with instructions to continue warfarin for 3-6 months in an outpatient setting.

\section{Discussion}

Vasectomy is a relatively safe and simple form of contraception. When compared to it gynecological counterpart (tubal ligation), vasectomies have a lower morbidity and mortality. A vasectomy is thirty times less-likely to fail and twenty times less-likely to have post-operative complication [1]. However, side-effects of vasectomies do exist and include hematomas, pain, and failure of sterilization [2]. Nonetheless, thromboembolic events are not a known side-effect of the procedure.

Risk factors for venous thromboembolism can be classified into acquired, inherited, or mixed risk factors. Acquired risk factors can include the use of oral contraceptives [3], older age [4], underlying malignancy [5], trauma [6], prolonged immobilization [3, 6], and major and orthopedic surgery [3]. Minor outpatient procedures, such as a vasectomy, are not considered a major risk factor.

The cause of the venous thromboembolism after a minor procedure may be the combination of venous stasis along with procedural inflammation $[6,7]$. However, our patient was immobilized for an extremely brief period of time. He was active and on his feet regularly. No other major risk factors were noted in our patient. He was a healthy 32 -year-old male. He was active in sports. He did not smoke. He would be thought of as being at extremely low risk of developing a pulmonary embolism subsequently after a procedure, especially one as quick and simple as an outpatient vasectomy. He presented to the Emergency Department on post-operative day number 26 after the procedure. With several weeks having passed after the vasectomy, one would assume the procedural inflammation would have resolved. Therefore, both theories of procedural inflammation as well as venous stasis seem unlikely in our patient adding to the unexpected presentation of our patient.

One may wonder if coagulation changes may occur after a vasectomy. A study by Kisker et al. [8] studied coagulation changes in primates following a vasectomy. They found no significant differences between their tested and control monkeys. Out of 30 primates studied, one showed an increase level in fibrin monomer, but he too did not show any evidence of thrombosis when examined post-mortem [8].

An association between a vasectomy and a pulmonary embolism has been suggested in the literature as early as 1968 [9]. In our review of the literature, we found only 5 reported cases of thromboembolic events occurring as associated with a vasectomy [9-13]. However, the time lapse in all the reported cases is of interest. The cases reported by Roberts find a time lapse of years between the incidents of multiple years between the vasectomy occurring and the time of the thrombophlebitis $[9,10]$. In our opinion, a time-lapse measured in years makes the association between the vasectomy and thromboembolic event to be more coincidental than causal. A third case reported by Alt [11] found a time-lapse of months between the vasectomy and the presentation of thrombophlebitis. Again, it is our opinion that the time-lapse measured in months also makes the association between the 2 occurrences to be more of association instead of causation. The final 2 reported cases show a short time-interval between the vasectomy and the thromboembolic event [12, 13]. These cases add support to our case of an association between the events being more of causation or relation over than of coincidental.

Pulmonary embolism has rarely been reported shortly after a vasectomy, but it should be recognized as a possible complication of the procedure. It is our opinion that such a complication is likely underreported and a better representation of it is needed in the literature. Urologists and other physicians need to be aware of the possibility that patients can develop venous thromboembolic events after such minor outpatient procedures. It may be worthwhile identifying high-risk patients and properly treating them with prophylactic medications. If not identified quickly, a pulmonary embolism can be fatal and can lead to significant morbidity and mortality in patients if left untreated. Therefore, the physicians that perform these procedures should educate their patients about signs and symptoms of a deep vein thrombosis and a pulmonary embolism so that the patient can seek immediate medical care if they suspect they are experiencing them. 


\section{References}

1 Adams CE, Wald M: Risks and complications of vasectomy. Urol Clin North Am 2009;36:331-336.

2 Awsare NS, Krishnan J, Boustead GB, Hanbury DC, McNicholas TA: Complications of vasectomy. Ann R Coll Surg Engl 2005;87: 406-410.

3 Rosendaal FR, Reitsma PH: Genetics of venous thrombosis. J Thromb Haemost 2009;7 (Suppl 1):301-304.

4 Bovill EG, van der Vliet A: Venous valvular stasis-associated hypoxia and thrombosis: what is the link? Annu Rev Physiol 2011;73: 527-545.
5 Stein PD, Beemath A, Meyers FA, Skaf E, Sanchez J, Olson RE: Incidence of venous thromboembolism in patients hospitalized with cancer. Am J Med 2006;119:60-68.

6 Martinelli I, Bucciarelli P, Mannucci PM: Thrombotic risk factors: basic pathophysiology. Crit Care Med 2010;38(2 Suppl):S3-9.

7 Reitsma PH, Versteeg HH, Middeldorp S: Mechanistic view of risk factors for venous thromboembolism. Arterioscler Thromb Vasc Biol 2012;32:563-568.

8 Kisker CT, Alexander NJ: Coagulation changes following vasectomy: a study in primates. Fertil Steril 1978;29:543-545.
9 Roberts HJ: Delayed thrombophlebitis and systemic complications after vasectomy: possible role of diabetogenic hyperinsulinism. J Am Geriatrics Soc 1968;16:267-280.

10 Roberts HJ: Thrombophlebitis after vasectomy. N Engl J Med 1971;284:1330.

11 Alt WJ: Thrombophlebitis and pulmonary emboli following vasectomy. Mich Med 1973;72:769-770.

12 Teachey DT: Saddle pulmonary embolism as a complication of vasectomy. Urology 2008; 71:e5-e6.

13 Cooke DA, Zazove P: Deep venous thrombosis after office vasectomy: a case report. J Med Case Rep 20104;4:242. 